\title{
Strength of Assembly Butt Joints of Plastic Pipes
}

\author{
Izabela Miturska ${ }^{1 *}$, Anna Rudawska', Valentina Brunella ${ }^{2}$ \\ 1 Lublin University of Technology, Faculty of Mechanical Engineering, Nadbystrzycka 36, 20-618 Lublin, Poland \\ 2 Department of Chemistry of the University of Turin, located in Via P. Giuria 7, 10125 Torino, Italy \\ * Corresponding author's e-mail: i.miturska@pollub.pl
}

\begin{abstract}
The aim of the study was to compare the welded and adhesive joints made of polypropylene pipes. The pipes were butt jointed. Two pipe diameters were used: $\varnothing 20 \mathrm{~mm}$ and $\varnothing 25 \mathrm{~mm}$. The welded joints were made by hot gas welding, while the adhesive joints were made by two epoxy adhesive compositions. The base for both compositions was Epidian 6 epoxy resin, which was mixed with IDA and TFF curing agents in the recommended quantitative ratios. The experimental tests consisted in determination and comparison of the strength properties of the made joints; therefore, the analyzed joints were subjected to the destructive strength tests, which determined their tensile strength in accordance with the ISO 527-1 standard. On the basis of the obtained results, it was observed that welded joints obtained the highest average strength. The lowest strength was characteristic for the adhesive joints made with Epidian 6/TFF/100:27 adhesive. The obtained results were subjected to a statistical analysis, which showed that the strength of $\varnothing 20 \mathrm{~mm}$ diameter pipe joints did not differ significantly from the strength of $\varnothing 25 \mathrm{~mm}$ diameter pipe joints, comparing the results for each type of joint with the assumed level of confidence $\alpha=0.05$.
\end{abstract}

Keywords: adhesive, welding, sleeve joints, permanent joints

\section{INTRODUCTION}

Joining the elements is an indispensable stage in the execution of many constructions. This is possible due to the assembly connections. Such connections are divided into permanent and temporary joints $[1,2,7]$. The permanent joints are those that cannot be disassembled in any way other than the complete destruction of the joint. The temporary bonds can be assembled and disassembled several times. The connections made in the process of adhesive bonding, welding, riveting or soldering belong to the group of inseparable connections, whereas inlet, snap-in or threaded connections belong to temporary connections.

Cohesion connections are being increasingly often used in various areas of technology. The development of well-known technologies and the introduction of new technologies in this field allow not only the combination of different metallic materials but also of ceramic and plastic materials $[1,29]$. An important aspect in the creation of the structures with bonded elements is their strength. The welded joints are among the best connections in this respect. There are a number of welding methods used in a variety of structures [5]. The great advantage of these connections is that they do not take too much time and are relatively easy to complete. However, the costs associated with the purchase of the welding equipment and consumables make it an expensive method [14, 30].

Frequently, it is necessary to combine the elements made of dissimilar materials. In such situations, adhesives play an important role. Joining the elements by means of adhesives has been known for a long time; however, it is only recently that it has started being used in the construction process and is a valuable addition to the existing methods of joining [22]. Adhesives have a wide range of applications in engineering, automotive, aviation, construction, medical, light industry, as well as in various areas of technology $[4,7]$. The adhesive bonds are durable and have a much lighter structure than the welded bonds. They have a number 
of advantages, such as corrosion resistance, sealing, vibration absorption and good insulating properties [27]. However, it should be noted that the cohesion connections made using different methods may have certain drawbacks and limitations, which may have a negative impact on the quality, strength and lifespan of the connection. Therefore, it is very important to choose the right method of joining and the accuracy of making the connections [24].

A comparison of the strength properties of butt welded and adhesive joints was presented in this paper. The joined elements were polypropylene pipes. The welding process was carried out by hot gas welding, while the adhesive joints were made with the use of two-component epoxy adhesive compositions. The experimental tests were carried out to determine which type of joints is more effective in terms of strength due to the bonding method.

\section{METHODS OF RESEARCH}

\section{Material used in the studies}

Plastics are increasingly used as basic construction materials, often being the only ones under given conditions. Their very wide variety in terms of structure and properties requires the knowledge of characteristic features before selection can be made.

Polypropylene (PP-R) pipes with a diameter of $\varnothing 20 \mathrm{~mm}$ and $\varnothing 25 \mathrm{~mm}$ were used for the experimental studies. The pipes were cut into $40 \mathrm{~mm}$ lengths. The edges of short pipes at the intersection were deburred and then, depending on the chosen method of assembly, their surface was subjected to appropriate treatments. The prepared samples were butt jointed.

Polypropylene (PP-R) is a thermoplastic material belonging to the group of olefin plastics. Owing to its properties and ease of processing, it can be subjected to bonding, welding, etc. It is characterized by corrosion resistance and low thermal conductivity; moreover, it does not react with water and its compounds $[8,28]$. Table 1 shows the selected properties of polypropylene.

Polypropylene pipes are very popular and easily accessible, making them the most commonly used polymer pipes in many industries. Polypropylene is mainly used in the chemical, pharmaceutical, electrotechnical, electronic and automotive industries. The PP-R pipes are also often used in hydraulic systems of hot and cold water, central heating, as well as sewage, drainage and protective systems $[6,10,21]$.

\section{Welded joints}

During the research, butt welded joints were made. The strength of the welded joints depends not only on the welded material itself, but is mainly related to a number of other factors resulting from the adopted welding technology. Hot gas welding was used to make the joints. The welding of polymeric materials is defined as the process of hot joining thermoplastic elements by plasticizing and melting their edges without exerting pressure [17, 31]. The most important is the process of welding in a hot gas stream, using welding rods acting as a bond. When selecting this material, the following basic principles should be accounted for: similar chemical compositions of the bonded material and the bond, the mechanical properties of the bond at least equal to those of the parent material. In this type of welding, the hot gas stream is usually air or - less frequently nitrogen and carbon dioxide. The use of nitrogen and carbon dioxide protects plastics against excessive oxidation at elevated temperatures. Excessive oxidation may occur during air application, especially when welding the plastics that are relatively easily oxidized.

The process of welding polypropylene pipes was carried out using a Yihua 992DA+ plastic welding machine. The basic parameters of gas leaving the burner were: temperature $-260^{\circ} \mathrm{C}$, pressure $-0.05 \mathrm{MPa}$. The material used as a binder is of the same type as the combined material,

Table. 1. Recommended operating parameters used in testing materials $[12,13,20]$

\begin{tabular}{|l|c|c|}
\hline \multicolumn{1}{|c|}{ Properties } & Value & Unit \\
\hline Density & $0.90-0.91$ & $\mathrm{~g} / \mathrm{cm}^{3}$ \\
\hline Melting point of crystallites & $69-75$ & ${ }^{\circ} \mathrm{C}$ \\
\hline Glass transition temperature & -35 & ${ }^{\circ} \mathrm{C}$ \\
\hline Vicat softening temperature & $135-150$ & ${ }^{\circ} \mathrm{C}$ \\
\hline Melting point & $160-165$ & ${ }^{\circ} \mathrm{C}$ \\
\hline Tensile strength & $1-3.6 \cdot 10^{7}$ & $\mathrm{~Pa}$ \\
\hline Breaking strength & $3-4 \cdot 10^{7}$ & $\mathrm{~Pa}$ \\
\hline Tensile elongation & $5-15$ & $\%$ \\
\hline Elongation at break & $500-700$ & $\%$ \\
\hline Compressive strength & $(0.7-1) \cdot 10^{8}$ & $\mathrm{~Pa}$ \\
\hline Specific heat at $23^{\circ} \mathrm{C}$ & 1.92 & $\mathrm{~J} /(\mathrm{g} \cdot \mathrm{K})$ \\
\hline Water absorption after $24 \mathrm{~h}$ & 0.03 & $\%$ \\
\hline
\end{tabular}


i.e. polypropylene. The connections were made in accordance with the recommendations of experts $[9,14,30]$. The surfaces of the elements to be connected are chamfered at an angle of $30^{\circ}$. During the welding process, the weld was made in one continuous passage. A schematic of the welded connections is shown in Figure 1.

The welding process was carried out under workshop conditions, in a draught-free room at $23^{\circ} \mathrm{C}$ at $24 \%$ air humidity. In total, 10 butt welded polypropylene pipes with diameters of $\varnothing 20 \mathrm{~mm}$ and Ø25 $\mathrm{mm}$ each were made.

\section{Adhesive joints}

The adhesive joints are made by inserting a thin layer of adhesive, referred to as an adhesive joint, between the surfaces of the joined elements. Dynamic development and more frequent use of adhesive technology is associated with the production of modern adhesives with much better properties $[7,11,18]$. The adhesive process consists of a number of steps, the most important of which are [23]:

- surface preparation for adhesive bonding,

- selection of the type, components and preparation of the adhesive mass,

- surface coating with adhesive,

- connecting the bonded parts and exerting pressure on the final joint,
- hardening and conditioning of constitutional joints.

In these bonding processes, the surface preparation of bonded parts consisted in unfolding the surface as well as removing dust and other contaminants from it. The surface was developed by mechanical cleaning with the use of an abrasive bulk tool in the form of the P120 grade abrasive paper, while the remaining impurities on the surface were removed at the stage of chemical cleaning with the use of an organic solvent, which was technical acetone.

Selection of the adhesive type and the method of bonding is determined by the type of bonded materials, working conditions of the joint and the required strength of the joint. Two epoxy adhesive compositions were used. Both compositions were based on the Epidian 6 epoxy resin, which was mixed with two different hardeners: IDA and TFF. Table 2 presents the composition and labelling of the adhesives. The stoichiometric ratio indicates the amount (in grams) of the hardener needed to cure 100 grams of resin.

Epidian 6 is an unmodified epoxy resin in the form of a viscous liquid with the consistency of a thick syrup and a light yellow colour. It is used to prepare an adhesive for cold bonding of materials such as metal, polymer materials, glass, porcelain, basalt, stoneware, etc. In addition, it is

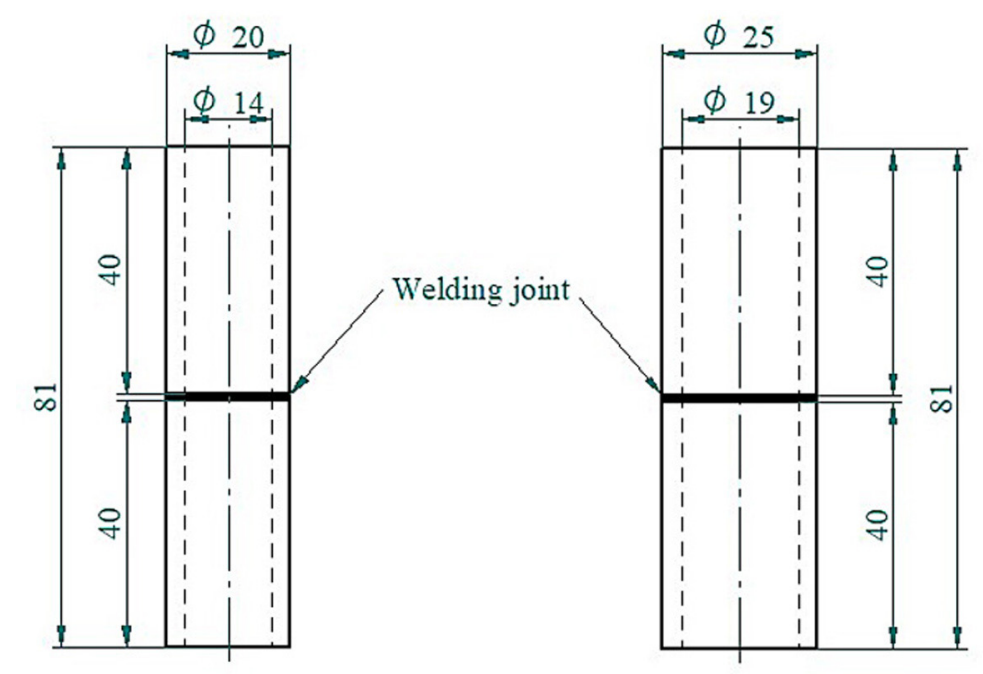

Fig. 1. Scheme of a butt welded joint made of polypropylene pipes with a diameter $\varnothing 20 \mathrm{~mm}$ and $\varnothing 25 \mathrm{~mm}$

Table 2. Composition of epoxy adhesives used in studies

\begin{tabular}{|c|c|c|c|c|}
\hline No. & Epoxy resin & Curing agent & Stoichiometric ratio & Labelling \\
\hline 1 & Epidian 6 & IDA & $100: 50$ & Epidian 6/IDA/100:50 \\
\hline 2 & Epidian 6 & TFF & $100: 27$ & Epidina 6/TFF/100:27 \\
\hline
\end{tabular}


also used to manufacture the linings for chemicalresistant tanks, fibre-reinforced pipes and mastics used in electrical engineering and electronics. The properties of this epoxy resin are presented in Table 3.

The IDA and TFF curing agents were used to harden the Epidian 6 resin. The IDA hardener is used mainly for hardening of floor masses. It enables to obtain a surface with perfect smoothness and high gloss. These surfaces also have good mechanical and chemically resistant properties. The IDA hardener can also be used to harden low molecular weight epoxy resins [15]. The gelation time of the IDA hardener mixed with Epidian 6 resin is about 40 minutes at $20^{\circ} \mathrm{C}$. The TFF hardener is used for hardening the epoxy compositions intended for the building industry, where work is carried out under the conditions of low temperature, often at high humidity. The good chemical resistance of such compositions in many aggressive environments qualifies the TFF hardener for the hardening of anti-corrosive linings in industry. The positive hygienic rating allows it to be used for various types of epoxy coatings in public utility rooms and in the food industry [16]. The gelation time of the Epidian 6 composition with the TFF hardener at $20^{\circ} \mathrm{C}$ is 17 minutes. Table 4 shows the properties of the hardeners used in the research.

The adhesive compositions were prepared directly before the process of bonding. The components of the mixtures were carefully weighed using a laboratory scale and then mixed with a mechanical mixer equipped with a propeller mixer. The mixing process with the speed of $460 \mathrm{rpm}$ lasted 2 minutes. Next, the adhesive compositions

Table 3. Properties of epoxy resin Epidian $6[3,26]$

\begin{tabular}{|l|c|c|}
\hline \multicolumn{1}{|c|}{ Property } & Value & Unit \\
\hline Boiling point & $>200$ & ${ }^{\circ} \mathrm{C}$ \\
\hline Flash point & $>200$ & ${ }^{\circ} \mathrm{C}$ \\
\hline Self-ignition temperature & $>500$ & ${ }^{\circ} \mathrm{C}$ \\
\hline Epoxy equivalent & $185-196$ & - \\
\hline Epoxy number & $0.51-0.54$ & $\mathrm{~mol} / 100 \mathrm{~g}$ \\
\hline Density at $20^{\circ} \mathrm{C}$ & 1.17 & $\mathrm{~g} / \mathrm{cm}^{3}$ \\
\hline Viscosity at $25^{\circ} \mathrm{C}$ & $10000-15000$ & $\mathrm{mPas}$ \\
\hline
\end{tabular}

were deaerated for 2 minutes in order to remove the gas bubbles formed as a result of mixing the components. The finished adhesive compositions were applied to the surfaces to be bonded using a roller for adhesive application, which enabled to achieve a homogeneous thickness of the joint across the entire adhesive surface. In the next stage, the elements were joined together. The joints thus formed were subjected to a single-step curing process at ambient temperature at a load of $1 \mathrm{~kg}$. The total curing time was 7 days. In order to avoid deformation of the joints, a special pipe holder was used after the assembly of the parts to be joined. This fixture prevented the surfaces to be joined from shifting relative to each other at the point of bonding, thus facilitating the axis alignment of the structure. Figure 2 shows the diagrams of adhesive joints made during the research.

The entire process of adhesive bonding, including surface preparation, was carried out under laboratory conditions at a temperature of $23 \pm 2{ }^{\circ} \mathrm{C}$ and an air humidity of $28 \pm 2 \%$. A total of 40 adhesive bonds were made during the experimental tests. For each diameter and each type of adhesive, 10 adhesive bonds were made.

\section{Strength tests}

After the assumed curing time, the welded and adhesive joints were exposed to the destructive strength tests on a Zwick / Roell Z150 testing machine. Testing was performed in accordance with ISO 527-1, with a preload of $20 \mathrm{~N}$ and a test speed of $5 \mathrm{~mm} / \mathrm{min}$. A special gripping fixture was used to secure the specimens to the jaws of the testing machine [25]. The tensile strength of the obtained joints could be determined by means of strength tests.

\section{RESULTS OF STRENGTH TESTS}

The comparison of the results of strength tests taking into account the diameter of the jointed pipes is presented in Figure 3.

Table. 4. Properties of the hardeners used in the tests $[15,16,19]$

\begin{tabular}{|l|c|c|}
\hline \multicolumn{1}{|c|}{ Property } & IDA curent agent & TFF curent agent \\
\hline Amine number & $200-350 \mathrm{mg} \mathrm{KOH} / \mathrm{g}$ & $500-700 \mathrm{mg} \mathrm{KOH} / \mathrm{g}$ \\
\hline Density at $20^{\circ} \mathrm{C}$ & $1.01-1.03 \mathrm{~g} / \mathrm{cm}^{3}$ & $1.15-1.20 \mathrm{~g} / \mathrm{cm}^{3}$ \\
\hline Viscosity at $25^{\circ} \mathrm{C}$ & $150-300 \mathrm{mPas}$ & Max. $10000 \mathrm{mPas}$ \\
\hline
\end{tabular}




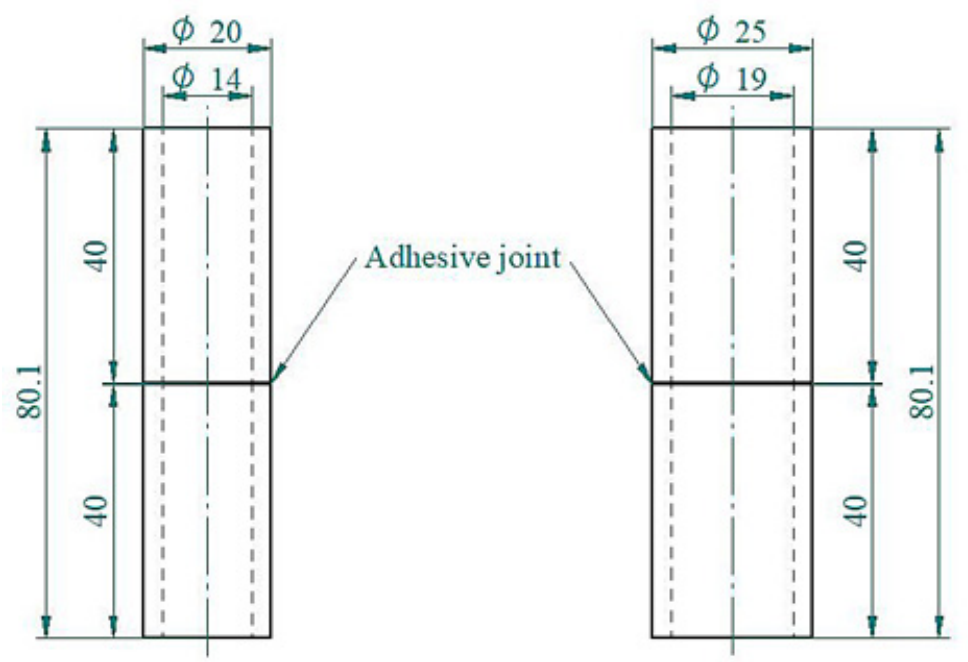

Fig. 2. Scheme of a butt adhesive joint made of polypropylene pipes with a diameter $\varnothing 20 \mathrm{~mm}$ and $\varnothing 25 \mathrm{~mm}$

On the basis of the presented test results, it can be observed that the welded joints achieved the highest average strength - for the joints of the samples of $\varnothing 20 \mathrm{~mm}$ diameter, the strength of $7.3 \mathrm{MPa}$ was obtained, while for the joints of the samples of $\varnothing 25 \mathrm{~mm}$ diameter, the average strength was $6.8 \mathrm{MPa}$. The worst results were obtained for the adhesive bonds made with Epidian 6/TFF/100:27. For the samples with the diameter of $\varnothing 20 \mathrm{~mm}$, the strength was $1.9 \mathrm{MPa}$ and for larger samples with diameter of $\varnothing 25 \mathrm{~mm}-2.1 \mathrm{MPa}$. It should be noted that the highest repeatability of the results was obtained for the welded joints. The process of adhesive bonding with the Epidian 6/TFF/100:27 adhesive composition turned out to be the least stable, estimating the repeatability of the obtained results. The standard deviation value was $0.3 \mathrm{MPa}$ (for samples of ø20 mm diameter) and $0.45 \mathrm{MPa}$ (for samples of $ø 25 \mathrm{~mm}$ diameter), which constitutes $16 \%$ and $22 \%$ of their average strength.

Taking into account the diameters of the parts to be joined, the differences between the results obtained for the various methods of assembling the connections are small. The best way to illustrate this is to use the interaction diagram in Figure 4, which shows that the distribution of results including the joining method is the same for both samples with a diameter of $\varnothing 20 \mathrm{~mm}$ and those with a larger diameter of $ø 25 \mathrm{~mm}$.

The strength of assembly connections is an important criterion for the assessment of such connections. However, in order to enable a comprehensive assessment of the connections obtained, it is necessary to carry out a statistical analysis of the results obtained. The assumption $(p>\alpha)$ of distribution normality (Shapiro-Wilk test) and variance homogeneity (Levene test)

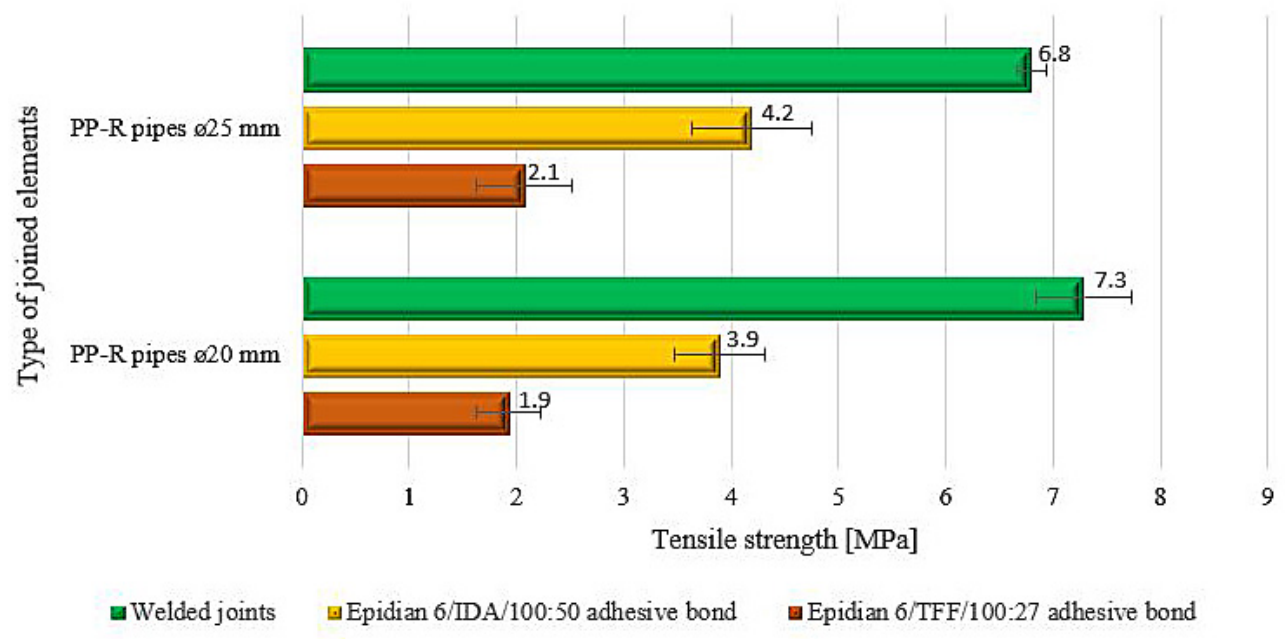

Fig. 3. Tensile strength of butt welded and adhesive joints of PP-R pipes 


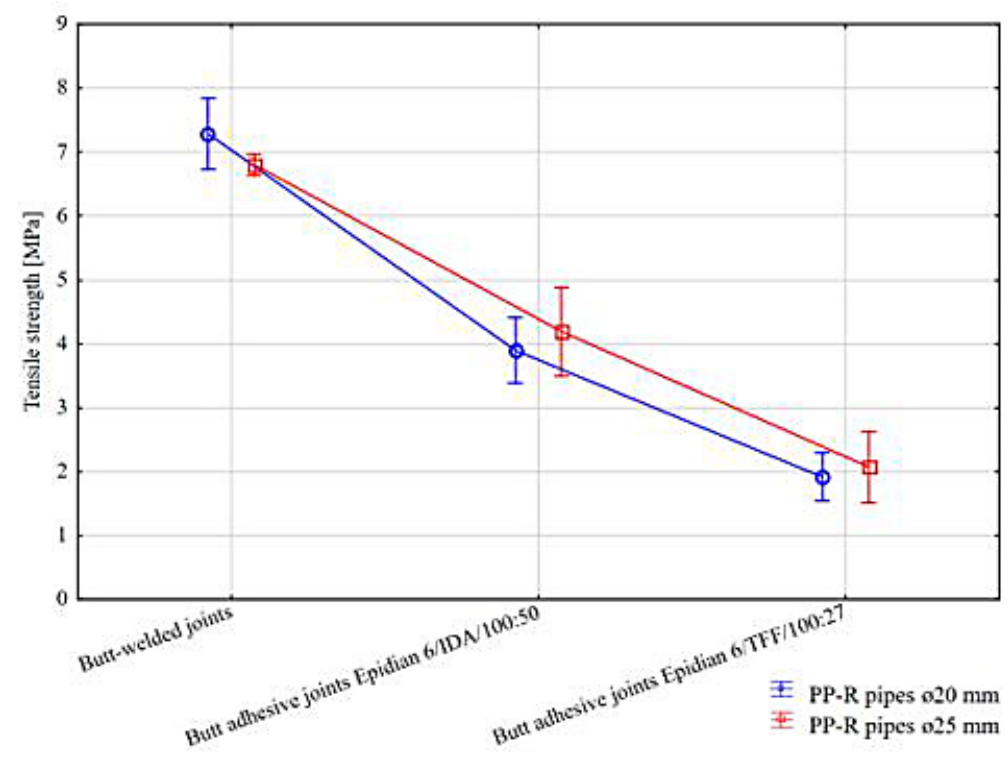

Fig. 4. Interaction diagram including assembly method and dimensions of the joined PP-R pipes

with the assumed confidence level $\alpha=0.05$ was fulfilled. The results of these tests are presented in Tables 5 and 6 . Therefore, parametric tests were used in the further stages of statistical analysis.

A Tukey RIR test was carried out to determine which type of connection is more advantageous in terms of strength and whether the differences are significant at the assumed materiality level $\alpha=0,05$. The results of this test are presented in Table 7.

On the basis of the results obtained, it can be observed that there are no significant differences between the pipes joints of different diameters made with particular methods of joining at the assumed level of significance $\alpha=0.05$. However, significant differences occur between the applied methods of joint making, i.e. the strength of welded joints of $\varnothing 20 \mathrm{~mm}$ diameter pipes does not differ significantly from the strength of the welded joints of $ø 25 \mathrm{~mm}$ diameter pipes, but they differ from the strength of adhesive joints made with adhesive compositions Epidian 6/IDA/100:50 and Epidian 6/TFF/100:27. The situation is similar in the case of adhesive joints made with both adhesives.

\section{CONCLUSIONS}

In the case of plastic structures, it is worth carefully considering the choice of assembly method because, as shown in the studies, the appropriate choice of technology has a significant impact on the results. The aim of the study was to compare the strength properties of butt welded joints and adhesive polypropylene pipes.

Table. 5. Results of the Shapiro-Wilk normality test

\begin{tabular}{|l|l|c|c|c|}
\hline \multicolumn{2}{|c|}{ Type of joint } & Shapiro-Wilk statistics W & Probability level $p$ & Normal distribution \\
\hline \multirow{2}{*}{ Butt-welded joints } & PP-R pipes $\varnothing 20 \mathrm{~mm}$ & 0.968859 & 0.867884 & Yes \\
\cline { 2 - 5 } & PP-R pipes $\varnothing 25 \mathrm{~mm}$ & 0.909967 & 0.467393 & Yes \\
\hline Butt adhesive joints & PP-R pipes $\varnothing 20 \mathrm{~mm}$ & 0.840582 & 0.166537 & Yes \\
\cline { 2 - 5 } Epidian 6/IDA/100:50 & PP-R pipes $\varnothing 25 \mathrm{~mm}$ & 0.832014 & 0.144029 & Yes \\
\hline Butt adhesive joints & PP-R pipes $\varnothing 20 \mathrm{~mm}$ & 0.944575 & 0.698438 & Yes \\
\cline { 2 - 5 } Epidian 6/TFF/100:27 & PP-R pipes $ø 25 \mathrm{~mm}$ & 0.862685 & 0.238050 & Yes \\
\hline
\end{tabular}

Table. 6. Levene test results of variance homogeneity

\begin{tabular}{|c|c|c|c|c|c|c|c|c|}
\hline & SS Effect & df Effect & MS Effect & SS Error & df Error & MS Error & F & $p$ \\
\hline $\begin{array}{c}\text { Tensile strength } \\
{[\mathrm{MPa}]}\end{array}$ & 0,380 & 5 & 0,077 & 0,859 & 24 & 0,036 & 2,125 & 0,097 \\
\hline
\end{tabular}


Table. 7. Tukey's test results for reasonable significant differences

\begin{tabular}{|c|c|c|c|c|c|c|c|c|}
\hline \multirow{2}{*}{\multicolumn{2}{|c|}{ Type of joint }} & \multirow{3}{*}{$\begin{array}{c}\begin{array}{c}\text { Average } \\
\text { tensile } \\
\text { strength }\end{array} \\
7.29\end{array}$} & \multicolumn{2}{|c|}{ Butt-welded joints } & \multicolumn{2}{|c|}{$\begin{array}{l}\text { Butt adhesive joints } \\
\text { Epidian 6/IDA/100:50 }\end{array}$} & \multicolumn{2}{|c|}{$\begin{array}{l}\text { Butt adhesive joints } \\
\text { Epidian 6/TFF/100:27 }\end{array}$} \\
\hline & & & \multirow{2}{*}{$\begin{array}{l}\text { PP-R pipes } \\
\varnothing 20 \mathrm{~mm} \\
\end{array}$} & \multirow{2}{*}{\begin{tabular}{|c|}
$\begin{array}{c}\text { PP-R pipes } \\
\varnothing 25 \mathrm{~mm}\end{array}$ \\
0.428122 \\
\end{tabular}} & \multirow{2}{*}{$\begin{array}{c}\text { PP-R pipes } \\
\varnothing 20 \mathrm{~mm} \\
0.000138\end{array}$} & \multirow{2}{*}{$\begin{array}{c}\begin{array}{c}\text { PP-R pipes } \\
\varnothing 25 \mathrm{~mm}\end{array} \\
0.000138\end{array}$} & \multirow{2}{*}{$\begin{array}{c}\begin{array}{c}\text { PP-R pipes } \\
\varnothing 20 \mathrm{~mm}\end{array} \\
0.000138\end{array}$} & \multirow{2}{*}{$\begin{array}{c}\begin{array}{c}\text { PP-R pipes } \\
\varnothing 25 \mathrm{~mm}\end{array} \\
0.000138\end{array}$} \\
\hline Butt-welded & $\begin{array}{l}\text { PP-R pipes } \\
ø 20 \mathrm{~mm}\end{array}$ & & & & & & & \\
\hline & $\begin{array}{l}\text { PP-R pipes } \\
\varnothing 25 \mathrm{~mm}\end{array}$ & 6.8 & 0.428122 & & 0.000138 & 0.000138 & 0.000138 & 0.000138 \\
\hline \multirow{2}{*}{$\begin{array}{l}\text { Butt adhesive } \\
\text { joints Epidian 6/ } \\
\text { IDA/100:50 }\end{array}$} & $\begin{array}{l}\text { PP-R pipes } \\
\varnothing 20 \mathrm{~mm}\end{array}$ & 3.89 & 0.000138 & 0.000138 & & 0.860671 & 0.000138 & 0.000140 \\
\hline & $\begin{array}{l}\text { PP-R pipes } \\
\varnothing 25 \mathrm{~mm}\end{array}$ & 4.19 & 0.000138 & 0.000138 & 0.860671 & & 0.000138 & 0.000138 \\
\hline \multirow{2}{*}{$\begin{array}{c}\text { Butt adhesive } \\
\text { joints Epidian 6/ } \\
\text { TFF/100:27 }\end{array}$} & $\begin{array}{l}\text { PP-R pipes } \\
\varnothing 20 \mathrm{~mm}\end{array}$ & 1.92 & 0.000138 & 0.000138 & 0.000138 & 0.000138 & & 0.990927 \\
\hline & $\begin{array}{l}\text { PP-R pipes } \\
ø 25 \mathrm{~mm}\end{array}$ & 2.07 & 0.000138 & 0.000138 & 0.000140 & 0.000138 & 0.990927 & \\
\hline
\end{tabular}

After experimental tests and analysis of the results, it was noticed that the highest average strength and the highest repeatability of the results were obtained in the case of welded joints. Among the adhesive bonds, higher strength was obtained for the bonds made with Epidian 6/IDA/100:50. Conversely, the lowest strength value was observed for the adhesive bonds made with Epidian 6/TFF/100:27 adhesive composition, and in this case the repeatability of the results was the lowest. It may prove that the process of welding polymeric materials is more stable in comparison to adhesive bonding. However, it should also be mentioned that the welding of polymer plastics is much more expensive compared to adhesive due to the necessary equipment and binders used in this process. Another explanation for the differences observed between the welded and adhesive bonds may be that polypropylene is a polyolefin polymeric material, a semi-crystalline thermoplastic and has a relatively high surface hardness. Therefore, it can be assumed that manual mechanical abrasive paper processing is not sufficient to prepare the surface of the bonded parts for the bonding process. The use of another method of developing the surface of a material such as polypropylene, e.g. by etching, could improve the strength properties of adhesive bonds. In addition, as mentioned above, the process of welding plastics is defined as the process of hot bonding thermoplastic elements by plasticizing and melting their edges, so that no other material than the parent material is introduced into the structure of such a bonding.

Moreover, it was observed that the size of the combined elements did not significantly influence the results obtained in this case. The strength of $ø 20 \mathrm{~mm}$ pipe connections is not significantly different from the strength of $\varnothing 25 \mathrm{~mm}$ pipe connections, comparing the results within each type of connection. Perhaps with wall pipes of different thicknesses the differences would be more significant.

The presented information may have a considerable impact on the design of welding and adhesive bonding technologies for polymeric materials. Other methods of surface preparation for the process of bonding polymeric materials are expected to be used in further studies..

\section{REFERENCES}

1. Banea M.D., da Silva L.F.M. Adhesively bonded joints in composite materials: An overview. Proceedings of the Institution of Mechanical Engineers, Part L: Journal of Materials: Design and Applications, 223, 1 2009, 1-18.

2. Bazrov B.M. Classification of joints. Russian Engineering Research, 30, 4, 2010, 399-403.

3. Brojer Z., Hertz Z., Penczek, P. Żywice epoksydowe. Wydawnictwa Naukowo-Techniczne, 1982.

4. Derewonko A., Godzimirski J., Kosiuczenko K., Niezgoda T., Kiczko, A. Strength assessment of adhesive-bonded joints. Computational Materials Science, 43, 1, 2008, 157-164.

5. Easterling K. Introduction to the Physical Metallurgy of Welding. Elsevier Science, 2014.

6. Geertz G., Brüll R., Wieser J., Maria R., Wenzel M., Engelsing K., Wüst J., Bastian M., Rudschuck M. Stabiliser diffusion in long-term pressure tested polypropylene pipes analysed by IR microscopy. Polymer Degradation and Stability, 94, 7, 2009, 1092-1102.

7. Godzimirski J. Structural Bonding Problems. 
Technologia i Automatyzacja Montażu, 1, 2009, 25-31.

8. Grebowicz J., Lau S.-F., Wunderlich B. The thermal properties of polypropylene. Journal of Polymer Science: Polymer Symposia, 71, 1, 2007, 19-37.

9. Grewell D.A., Bonten C. Plastics and composites welding handbook. Hanser, 2003.

10. Hametner Ch. Polypropylene pipes for drinking water supply. Journal of Macromolecular Science, Part A, 36, 11, 2007, 1751-1758.

11. Hartshorn S.R. Structural Adhesives Chemistry and Technology. Springer Verlag, 2013.

12. Karian H.G. Handbook of polypropylene and polypropylene composites. Marcel Dekker, 2003.

13. Kawasumi M., Hasegawa N., Kato M., Usuki A., Okada A. Preparation and Mechanical Properties of Polypropylene-Clay Hybrids. Macromolecules, 30, 20, 1997, 6333-6338.

14. Kou S. Welding metallurgy. MRS Bulletin, 28, 9, 2003, 674-675.

15. Kowalczyk K., Spychaj T. Epoxy coatings with modified montmorillonites. Progress in Organic Coatings, 62, 4, 2008, 425-429.

16. Kucharczyk W., Dusiński D., Żurowski W., Gumiński R. Effect of composition on ablative properties of epoxy composites modified with expanded perlite. Composite Structures, 183, 2018, 654-662.

17. Mingareev I., Weirauch F., Olowinsky A., Shah L., Kadwani P., Richardson M. Welding of polymers using a $2 \mu \mathrm{m}$ thulium fiber laser. Optics \& Laser Technology, 44, 7, 2012, 2095-2099.

18. Mirski Z., Piwowarczyk T. The history of bonding - from prehistory to today. Welding Technology Review, 80, 8, 2008, 3-11.

19. Mohan P. Critical Review: The Modification, Properties, and Applications of Epoxy Resins. PolymerPlastics Technology and Engineering, 52, 2, 2013 , 107-125.
20. Natta G., Corradini P. Structure and properties of isotactic polypropylene. Il Nuovo Cimento, 15, S1, 2007, 40-51.

21. Poduška J., Kučera J., Hutař P., Ševčík M., Křivánek J., Sadílek J., Náhlík L. Residual stress distribution in extruded polypropylene pipes. Polymer Testing, 40, 2014, 88-98.

22. Porębska M., Skorupa A. Połączenia spójnościowe. Wydawnictwo Naukowe PWN, 2013.

23. Rudawska A., Kuczmaszewski J. Klejenie blach ocynkowanych. Wydawnictwo Politechniki Lubelskiej, 2005.

24. Rudawska A., Maziarz M., Miturska I. Impact of Selected Structural, Material and Exploitation Factors on Adhesive Joints Strength. MATEC Web of Conferences, 252, 2019, 01006.

25. Rudawska A., Warda T. Fixing and fixing holder, especially butt adhesive sleeves. 2016.

26. Stabik J., Dybowska A. Electrical and tribological properties of gradient epoxy-graphite composites. Journal of Achievements in Materials and Manufacturing Engineering, 27, 1, 2008, 39-42.

27. Stoeckel F., Konnerth J., Gindl-Altmutter W. Mechanical properties of adhesives for bonding woodA review. International Journal of Adhesion and Adhesives, 45, 2013, 32-41.

28. Svoboda P., Zeng C., Wang H., Lee L.J., Tomasko D.L. Morphology and mechanical properties of polypropylene/organoclay nanocomposites. Journal of Applied Polymer Science, 85, 7, 2002, $1562-1570$

29. Tong L., Steven G.P. Analysis and design of structural bonded joints. Kluwer Academic, 1999.

30. Weman K. Welding processes handbook. Woodhead Pub, 2012.

31. Wise R.J. Thermal welding of polymers. Abington, 1999. 